\title{
The Nitric Oxide-cGMP Pathway May Mediate Communication between Sensory Afferents and Projection Neurons in the Antennal Lobe of Manduca Sexta
}

\author{
Alan Nighorn, ${ }^{1}$ Nicholas J. Gibson,, ${ }^{1}$ David M. Rivers, ${ }^{1}$ John G. Hildebrand, ${ }^{1}$ and David B. Morton ${ }^{2}$ \\ ${ }^{1}$ Arizona Research Laboratories, Division of Neurobiology, University of Arizona, Tucson, Arizona 85721, and ${ }^{2}$ Department \\ of Biological Structure and Function, School of Dentistry, Oregon Health Sciences University, Portland, Oregon 97201
}

The nitric oxide (NO)-cGMP signaling system is thought to play important roles in the function of the olfactory system in both vertebrates and invertebrates. One way of studying the role of $\mathrm{NO}$ in the nervous system is to study the distribution and properties of NO synthase (NOS), as well as the soluble guanylyl cyclases (sGCs), which are the best characterized targets of NO. We study NOS and SGC in the relatively simple and well characterized insect olfactory system of the hawkmoth, Manduca sexta. We have cloned Manduca sexta nitric oxide synthase (MsNOS) and two sGCs (MsGC $\alpha 1$ and MsGC $\beta 1$ ), characterized their basic biochemical properties, and studied their expression in the olfactory system. The sequences of the Manduca genes are highly similar to their mammalian homologs and show similar biochemical properties when expressed in
COS-7 cells. In particular, we find that MsGC functions as an obligate heterodimer that is stimulated significantly by NO. We also find that MsNOS has a $\mathrm{Ca}^{2+}$-sensitive $\mathrm{NO}$-producing activity similar to that of mammalian neuronal NOS. Northern and in situ hybridization analyses show that MsNOS and the MsGCs are expressed in a complementary pattern, with MsNOS expressed at high levels in the antennae and the MsGCs expressed at high levels in a subset of antennal lobe neurons. The expression patterns of these genes suggest that the NOsGC signaling system may play a role in mediating communication between olfactory receptor neurons and projection neurons in the glomeruli of the antennal lobe.

Key words: nitric oxide synthase; soluble guanylyl cyclase; Manduca sexta; olfaction; cGMP; NO
Nitric oxide (NO) has been shown to play many roles in the function of the nervous system as an intercellular and intracellular messenger (O’Dell et al., 1991; Schuman and Madison, 1994). A good model system in which to examine the roles of NO is the olfactory system, particularly the first synaptic neuropil: the olfactory bulb in mammals and the antennal lobe in insects (Breer and Shepherd, 1993). One way to do this is to examine the distribution of NO synthase (NOS) and soluble guanylyl cyclase (sGC), the best characterized target of NO. In situ hybridization and immunohistochemical and histochemical studies in mammals have shown that NOS and sGC are expressed at high levels in the olfactory bulb (Kishimoto et al., 1993; Hopkins et al., 1996).

In insects, studies have focused on the antennal lobe, a structure both functionally and anatomically similar to the olfactory bulb. In the antennal lobe, sensory axons from the antennae and inhibitory interneurons and projection neurons of the antennal lobe enter into complex synaptic arrangements within spheroidal neuropils called glomeruli. Sensory afferents project to the outer margin, interneurons form dense arborizations more medially, and neurites of projection neurons occupy the basal margin of each glomerulus. The location of NOS within the antennal lobe has been investigated primarily using the histochemical stain for NADPH-diaphorase, an activity that frequently colocalizes with

\footnotetext{
Received May 18, 1998; revised July 1, 1998; accepted July 6, 1998.

Correspondence should be addressed to Dr. Alan Nighorn, Arizona Research Laboratories, Division of Neurobiology, University of Arizona, Tuscon, AZ 85721.

This work was supported by National Science Foundation Grant IBN9604536 (A.N.) and National Institutes of Health Grants NS23253 (J.G.H.) and NS29740 (D.B.M.). We thank Mark Higgins for his invaluable technical assistance and Leslie Tolbert, Sharon Hesterlee, and Jeanette Simpson for their helpful review of this manuscript. We also thank Dr. David Bredt for his gift of the rat nNOS clone. Copyright (C) 1998 Society for Neuroscience $0270-6474 / 98 / 187244-12 \$ 05.00 / 0$
}

NOS (Schmidt et al., 1992). In these studies, high levels of NADPH-diaphorase activity was found in the antennal lobes, both in the glomeruli and in the groups of neuronal somata bordering the neuropil (Elphick et al., 1995; Müller and Hildebrandt, 1995; Bicker et al., 1996; Schachtner et al., 1998). It is unclear, however, whether this staining pattern accurately and specifically reflects the distribution of the NOS enzyme.

The distribution of NOS and sGC in the olfactory bulb of vertebrates and of NADPH-diaphorase staining in the antennal lobes of insects suggests that the NO-cGMP signaling system plays important roles in the processing of olfactory information. It has been suggested that each glomerulus, a spheroidal module of neuropil surrounded by a glial sheath, might be an ideal domain for NO to coordinate neural activity (Breer and Shepherd, 1993). The NO-sGC signaling system also might mediate olfactory synaptic plasticity. Indeed, evidence for a form of olfactory learning mediated by NO-sGC has been found in mice (Okere et al., 1996), sheep (Kendrick et al., 1997), and honeybees (Müller, 1996).

In this paper, we examine the roles of the NO-cGMP signaling system in the olfactory system of Manduca sexta. We clone Manduca NOS and sGC and characterize their biochemical properties in vitro and their expression patterns in vivo. We find that these enzymes have the expected activities but a surprising expression pattern. This expression pattern suggests that NADPHdiaphorase staining may not accurately reflect NOS distribution. More importantly, this expression pattern also suggests that the NO-cGMP signaling system may mediate direct communication between sensory afferents and projection neurons in the antennal lobe. 


\section{MATERIALS AND METHODS}

Animals. Manduca sexta (Lepidoptera: Sphingidae) were reared in a laboratory culture on an artificial diet as previously described (Sanes and Hildebrand, 1976; Prescott et al., 1977). Animals used in the present study were at stage 18 of adult development, $\sim 4-8 \mathrm{hr}$ before the expected time of adult ecdysis (Tolbert et al., 1983) or $4 \mathrm{hr}$ before ecdysis to the pupal stage, and were staged according to external morphological markers (Truman et al., 1980).

$R N A$ isolation and degenerate oligo reverse transcription-PCR. Total RNA was isolated from ventral nerve cords of prepupae with the aid of Trizol reagent (Life Technologies, Gaithersburg, $\mathrm{MD}$ ). The poly $\left(\mathrm{A}^{+}\right)$ RNA fraction was purified using oligo-dT cellulose columns (Life Technologies). First-strand cDNA was then generated from $5 \mu \mathrm{g}$ of poly $\left(\mathrm{A}^{+}\right)$ RNA using oligo-dT primers and Superscript II RT (Life Technologies). The cDNA was then resuspended in $40 \mu \mathrm{l}$ of water. To clone sGCs, degenerate oligonucleotide primers were designed against the amino acid sequences DVYKVETI (CCRAAIARRCARTAICKNGGCAT) and MPRYCLFG (GAYGTITAYAARGTIGWIACNAT) from the putative catalytic domain common to both sGCs and receptor guanylyl cyclases (rGCs) (Chinkers and Garbers, 1991). PCR was performed in a $20 \mu \mathrm{l}$ reaction containing $1 \mu \mathrm{l}$ of cDNA from the above reaction, 200 pmols of each degenerate primer, $2 \mathrm{~mm} \mathrm{MgCl}_{2}, 1 \times$ PCR buffer II (Perkin-Elmer, Foster City, CA), all four deoxynucleotides at $200 \mu \mathrm{M}$, $12.5 \mu \mathrm{Ci}$ of $\left[{ }^{35} \mathrm{~S}\right] \mathrm{dATP}$, and $2 \mathrm{U}$ of Amplitaq (Perkin-Elmer). Thirty cycles were performed on a thermocycler (9600; Perkin-Elmer) at $94^{\circ} \mathrm{C}$ for $20 \mathrm{sec}, 50^{\circ} \mathrm{C}$ for $20 \mathrm{sec}$, and $72^{\circ} \mathrm{C}$ for $30 \mathrm{sec}$. Because the amplified domain of sGCs is three to six nucleotides shorter than that of rGCs, the resulting PCR products were analyzed on an $8 \%$ polyacrylamide sequencing gel. Bands that were below the $235 \mathrm{bp}$ expected size of the receptor GCs were cut out, eluted in TE, and reamplified using the same conditions without the $\left[{ }^{35} \mathrm{~S}\right] \mathrm{dATP}$. The PCR products were T/A cloned into the vector pCRII (Invitrogen, Carlsbad, CA) and manually sequenced. To clone NOS, degenerate oligonucleotide primers were generated against the conserved amino acids WYMS/GTEIG (TGGTAYATGISNACNGARATHGG) and PVFHQEM (CATYTGRTGTAANACNGG). PCR was performed as described above, except that $\left[{ }^{35} \mathrm{~S}\right] \mathrm{dATP}$ was not added, and the products were analyzed on a $1 \%$ agarose gel. A band of $330 \mathrm{bp}$ was electroeluted, T/A cloned, and sequenced. Note that there is a mismatch at the $3^{\prime}$ end of the $3^{\prime}$ primer compared with the Manduca sexta nitric oxide synthase (MsNOS) sequence (see Fig. 1). The MsNOS PCR product was obtained, because some truncated degenerate oligos remained in the oligo mixture as a result of incomplete synthesis.

Reverse transcription-PCR. Total RNA was isolated from ventral nerve cords and antennal lobes using Trizol (Life Technologies). Aliquots (5 $\mu \mathrm{g}$ ) of the total RNA were treated with DNaseI (Life Technologies) for $30 \mathrm{~min}$ at $37^{\circ} \mathrm{C}$. Reverse transcription (RT) was then performed using oligo-dT primers and Superscript RT in a $20 \mu \mathrm{l}$ total volume for $1 \mathrm{hr}$ at $37^{\circ} \mathrm{C}$. Control reactions performed in parallel omitted the RT. The cDNA was diluted to $40 \mu \mathrm{l}$ with water. PCR was performed in a $20 \mu \mathrm{l}$ reaction containing $1 \mu \mathrm{l}$ of cDNA from the above reaction, 200 pmols of each primer, $2 \mathrm{mM} \mathrm{MgCl}_{2}, 1 \times \mathrm{PCR}$ buffer II (Perkin-Elmer), all four deoxynucleotides at $200 \mu \mathrm{M}$ each, and $2 \mathrm{U}$ of Amplitaq Gold (Perkin-Elmer). Thirty cycles were performed on a thermocycler (9600; Perkin-Elmer) at $94^{\circ} \mathrm{C}$ for $20 \mathrm{sec}, 68^{\circ} \mathrm{C}$ for $20 \mathrm{sec}$, and $72^{\circ} \mathrm{C}$ for $30 \mathrm{sec}$. Products were then analyzed on a $1 \%$ agarose gel and stained with ethidium bromide. The primers for MsGC $\alpha 1$ and MsNOS were designed using Oligo 4.0 (National Biosciences, Plymouth, MN). The primers for MsGC $\alpha 1$ were TCACTGCTGTGTTCCGAT and ATAGAAGGCCGTGGTCTT. The primers for MsNOS were CATCATAGACGGCACCAG and TCACTGCTGTGTTCCGAT.

${ }^{32}$ P-labeled probe generation. $\alpha-{ }^{32} \mathrm{P}$-labeled single-stranded DNA probes were generated in a $20 \mu \mathrm{l}$ PCR reaction that contained $50 \mathrm{ng}$ of linearized template DNA, 200 pmol of specific primer, $200 \mu \mathrm{M}$ dATP, $200 \mu \mathrm{M}$ dGTP, $200 \mu \mathrm{M}$ dTTP, $50 \mu \mathrm{Ci}$ of $\left[\alpha^{-{ }^{3}} \mathrm{P}\right] \mathrm{dCTP}(3000 \mathrm{mCi} / \mathrm{ml}), 2$ $\mathrm{mM} \mathrm{MgCl} l_{2}, 1 \times$ PCR buffer II, and $2 \mathrm{U}$ of Amplitaq Gold (PerkinElmer). PCR (35 cycles) was performed with a Perkin-Elmer 9600 thermocycler at $94^{\circ} \mathrm{C}$ for $20 \mathrm{sec}, 50^{\circ} \mathrm{C}$ for $30 \mathrm{sec}$, and $72^{\circ} \mathrm{C}$ for $5 \mathrm{~min}$. Unincorporated nucleotides were removed by precipitation with ammonium acetate and ethanol.

Random priming. Random labeling was performed on gel-purified linearized templates with the Decaprime kit (Ambion, Austin, TX) using $\left[{ }^{32} \mathrm{P}\right] \mathrm{dCTP}$.

cDNA library construction and screening. cDNA libraries were constructed from $5 \mu \mathrm{g}$ of poly $\left(\mathrm{A}^{+}\right)$RNA and purified as described above from stage 18 antennae and prepupal ventral nerve cords. Oligo-dTprimed double-stranded cDNA was generated using a Superscript Choice cDNA construction kit (Life Technologies) according to the manufacturer's instructions, except that the RT reaction was performed in a thermocycler at $37^{\circ} \mathrm{C}$ for $15 \mathrm{~min}$, followed by a slow rise to $50^{\circ} \mathrm{C}$ over the following $45 \mathrm{~min}$. Adapted cDNA was then ligated into EcoRI cut Lambda-ZAPII (Stratagene, La Jolla, CA) and packaged using Gigapack Gold III (Stratagene) packaging extract. The library was screened using nitrocellulose filters (Schleicher \& Schuell, Keene, NH) that were hybridized and washed according to the manufacturer's instructions. Positive clones were sequenced in both directions using automated sequencing (Perkin-Elmer) and a primer walking strategy with sequencing primers designed using Oligo 4.0 (NBI).

5' Rapid amplification of cDNA ends. 5' Rapid amplification of cDNA ends (RACE) was performed to confirm the $5^{\prime}$ end of the MsNOS gene. Five micrograms of poly $\left(\mathrm{A}^{+}\right)$RNA isolated from antennae (see above) was used to generate adapted double stranded cDNA with the Marathon kit (Clontech, Palo Alto, CA). PCR was then performed with the adapter primer and the MsNOS-specific primer CATGAGGCTGGTCTGGCATAC under the following conditions using ExTaq DNA polymerase (TaKaRa): 30 cycles at $94^{\circ} \mathrm{C}$ for $30 \mathrm{sec}$ and at $68^{\circ} \mathrm{C}$ for $4 \mathrm{~min}$. The resulting PCR products were analyzed on a $0.9 \%$ agarose gel, T/A cloned, and sequenced.

DNA sequencing and sequence analysis. Manual DNA sequencing was performed using the Sequenase 2.0 kit (Amersham, Arlington Heights, IL). Most sequencing was done by an automated sequencing facility running an Applied Biosystems (Foster City, CA) 377 sequencer. Sequence analysis was performed on a Macintosh LC475 computer running Geneworks DNA analysis software (Oxford Molecular Group, Campbell, CA). Protein sequence alignments were performed using the CLUSTAL W program (Thompson et al., 1994) through the Baylor College of Medicine search launcher.

Northern blot analysis. Poly $\left(\mathrm{A}^{+}\right)$RNA was separated on a formaldehyde-agarose $(1 \%)$ gel and blotted onto Zetaprobe membrane (BioRad, Hercules, CA) using capillary transfer. The blot was UV crosslinked, dried completely, and hybridized overnight at $42^{\circ} \mathrm{C}$ with a hybridization solution consisting of $50 \%$ formamide, $5 \times$ SSPE, $5 \times$ Denhardt's solution, $1 \%$ SDS, $10 \%$ dextran sulfate, $100 \mu \mathrm{g} / \mathrm{ml}$ sonicated salmon sperm DNA, and ${ }^{32} \mathrm{P}-$ labeled probe at $10^{6} \mathrm{cpm} / \mathrm{ml}$. Probes were generated by random priming using the entire gel-purified cDNA clone as a template.

Cell transfections and enzyme assays. The open reading frames for MsNOS, MsGC $\alpha 1$, and MsGC $\beta 1$ were cloned into pcDNA3.1 (Invitrogen), and $8 \mu \mathrm{g}$ of each plasmid was transfected into a $10 \mathrm{~cm}$ dish of COS-7 cells using Lipofectamine (Life Technologies). Three days after transfection, the cells were harvested and assayed for either NOS or GC activity. For NOS activity, the cells were homogenized in $1 \mathrm{ml}$ of $25 \mathrm{~mm}$ Tris-HCl, $100 \mathrm{~mm} \mathrm{NaCl}, 1 \mathrm{~mm}$ EDTA, $1 \mathrm{~mm}$ EGTA, and $1 \mathrm{~mm}$ PMSF, $\mathrm{pH} 7.4$, and assayed for their ability to convert $\left[{ }^{3} \mathrm{H}\right]$ arginine to $\left[{ }^{3} \mathrm{H}\right]$ citrulline as described previously (Bredt and Schmidt, 1996). As a comparison, pcDNA3.1 containing rat neuronal NOS (nNOS) [kindly supplied by Dr. David Bredt, University of California at San Francisco (UCSF), San Francisco, CA] was also transfected into COS-7 cells and assayed in parallel. For GC assays, the cells were harvested and homogenized in 1 $\mathrm{ml}$ of $25 \mathrm{~mm}$ Tris- $\mathrm{HCl}$ and $1 \mathrm{~mm}$ PMSF, pH 7.4, and assayed for their ability to convert $\left[\alpha{ }^{-3} \mathrm{P}\right] \mathrm{GTP}$ to $\left[\alpha-{ }^{32} \mathrm{P}\right] \mathrm{cGMP}$ in the presence or absence of $250 \mu \mathrm{M}$ sodium nitroprusside (SNP) as described previously (Morton and Giunta, 1992).

Riboprobe generation. Digoxigenin (Boehringer Mannheim, Indianapolis, IN)-labeled riboprobes used for in situ hybridization were generated in both the sense and antisense directions with T3 and T7 RNA polymerase (Life Technologies) as described previously (Komminoth, 1996). The entire linearized cDNA clone for each gene was used as a template. The resulting riboprobes were then hydrolyzed to an average size of 200 nucleotides using alkaline hydrolysis as described previously (Angerer and Angerer, 1992).

In situ hybridization. In situ hybridization was performed using modifications of a protocol described by Komminoth (1996). Briefly, brains of pharate adult Manduca were dissected and fixed in $4 \%$ paraformaldehyde in PBS overnight at $4^{\circ} \mathrm{C}$. Frozen sections $(20 \mu \mathrm{m})$ were then cut, mounted onto Superfrost slides (Electron Microscopy Sciences, Fort Washington, PA), and incubated overnight at $42^{\circ} \mathrm{C}$. The slides were then pretreated with a 15 min wash in PBST, a 20 min incubation in $0.2 \mathrm{~N} \mathrm{HCl}$, a $10 \mathrm{~min}$ wash in $2 \times \mathrm{SSPE}$, a $30 \mathrm{~min}$ incubation with $2 \mathrm{mg} / \mathrm{ml}$ proteinase $\mathrm{K}$ in TE at $37^{\circ} \mathrm{C}$, a $10 \mathrm{~min}$ fix in $4 \%$ paraformaldehyde in PBS at $4^{\circ} \mathrm{C}$, and a $10 \mathrm{~min}$ 
incubation in $0.1 \%$ acetic anhydride in $0.1 \mathrm{M}$ triethanolamine, $\mathrm{pH}$ 8.0. The slides were washed in PBS between each of the steps in the pretreatment. The slides were then hybridized overnight at $42^{\circ} \mathrm{C}$ in $50 \%$ formamide, $10 \%$ dextran sulfate, $1 \times$ Denhardt's solution, $4 \times$ SSPE, 500 $\mu \mathrm{g} / \mathrm{ml}$ yeast tRNA, $250 \mu \mathrm{g} / \mathrm{ml}$ sonicated salmon sperm DNA, and $\sim 5 \mathrm{ng}$ of digoxigenin-labeled riboprobe. Equal amounts of a sense riboprobe were used as a negative control. After hybridization, the slides were washed $2 \times$ for $15 \mathrm{~min}$ in $2 \times \mathrm{SSPE}$, incubated for $30 \mathrm{~min}$ at $37^{\circ} \mathrm{C}$ with 20 $\mu \mathrm{g} / \mathrm{ml} \mathrm{RNaseA}$, and washed $2 \times$ for $15 \mathrm{~min}$ in $0.1 \times \mathrm{SSPE}$ at $50^{\circ} \mathrm{C}$. The probes were then visualized by incubation in alkaline phosphataselabeled sheep anti-digoxigenin antibody (Boehringer Mannheim) at 1:1000 dilution in TBST overnight at $4^{\circ} \mathrm{C}$. The slides were washed $4 \times$ for 15 min in TBS. The staining was developed using a BCIP-NBT solution (Amresco, Solon, OH), and the slides were mounted using Gel/Mount (Biomeda, Foster City, CA).

cGMP immunohistochemistry. The brains of pharate adult Manduca were dissected in HBSS (Sigma, St. Louis, MO) and incubated for $15 \mathrm{~min}$ in either saline or saline with $1 \mathrm{mM}$ SNP (Sigma) added. The brains were then fixed overnight in $4 \%$ paraformaldehyde at $4^{\circ} \mathrm{C}$. The brains were mounted in $7 \%$ low-melt agarose, and $50 \mu \mathrm{m}$ vibratome sections were cut. The sections were blocked (PBS, $0.3 \%$ Triton X-100, and $2 \%$ normal goat serum) for $1 \mathrm{hr}$ at room temperature and incubated with sheep anti-cGMP antisera (H. Steinbusch, University of Limburg, The Netherlands) diluted 1:20,000 in blocking solution at $4^{\circ} \mathrm{C}$ overnight. The slides were washed with PBST and then incubated in HRP-conjugated antisheep (Jackson ImmunoResearch, West Grove, PA) at $2^{\circ} \mathrm{C}$ diluted 1:1000 in blocking solution at $4^{\circ} \mathrm{C}$ overnight. The slides were then washed, developed with $0.5 \mathrm{mg} / \mathrm{ml}$ diaminobenzidine in the presence of $0.03 \%$ hydrogen peroxide, and mounted with Gel/Mount (Biomeda).

\section{RESULTS}

\section{Manduca sexta NOS is similar to mammalian nNOS}

We used degenerate oligo RT-PCR with primers designed against amino acid sequences just upstream of the tetrahydrobiopterinbinding domain (Fig. 1) to amplify a product from Manduca nervous system RNA. The resulting band of $330 \mathrm{bp}$ was cloned and sequenced. Fifteen independent clones were obtained, all of which contained an identical cDNA sequence with high similarity to known NOS clones from other species. This probe was then used to screen two independent cDNA libraries (see Materials and Methods). We obtained identical 5854 bp clones from both libraries. This 5854 bp clone contains an open reading frame extending from an initial methionine at base pair 100 to a termination codon at base pair 3717 , resulting in a putative protein product of 1206 amino acids. There are no stop codons upstream of the initial methionine, but the $5^{\prime}$ end of the clone was confirmed by comparison of clones from the two different cDNA libraries. We obtained the same $5^{\prime}$ end of the gene using $5^{\prime}$ RACE. Northern blot analysis (see Fig. 5) also shows a clone of 5.8-6.0 kb. All of the above evidence suggests that we have obtained a full-length cDNA clone of NOS from Manduca sexta.

Sequence comparisons of the MsNOS clone with other cloned NOS genes from both mammalian and insect species have shown that MsNOS is more closely related to the other known insect NOS genes (52\% identical to Rhodnius NOS and $47 \%$ identical to Drosophila NOS) (Regulski and Tully, 1995; Yuda et al., 1996) than to any of the mammalian NOS isoforms. Of the mammalian isoforms, MsNOS is more closely related to neuronal NOS (nNOS or NOS1) than to either inducible NOS (iNOS or NOS2) or endothelial NOS (eNOS or NOS3). Alignment of MsNOS with the rat nNOS gene shows that MsNOS contains all of the cofactor- and heme- binding domains present in nNOS (Fig. 1). The MsNOS clone, however, does not contain the amino terminal extension present in nNOS, which contains the PDZ and PIN domains that are important for the subcellular localization and regulation of the function of nNOS (Brenman et al., 1996; Jaffrey and Snyder, 1996). Like the NOS cloned from Rhodnius (Yuda et al., 1996), MsNOS does not contain the amino terminal extension of unknown function that is present in the Drosophila NOS gene (Regulski and Tully, 1995). Nevertheless, the MsNOS clone does appear to represent a genuine Manduca NOS with all of the essential biochemical domains necessary for the calciumdependent generation of NO.

\section{Manduca sexta expresses $\alpha$ and $\beta$ isoforms of sGC}

There are two main classes of guanylyl cyclases: rGC and sGC. Active sGC is a heme-containing heterodimer consisting of an $\alpha$ and a $\beta$ subunit. Both subunits have catalytic, dimerization, and heme-binding domains (Wedel et al., 1995). The rGCs are thought to act as homodimers and consist of catalytic, dimerization, kinase-like, transmembrane, and extracellular ligandbinding domains (Garbers, 1992). The catalytic domains of rGCs and sGCs are highly conserved. We used degenerate oligo RTPCR to amplify a section of this conserved catalytic domain (Nakane and Murad, 1994) present in both rGCs and sGCs. We obtained a band of $230 \mathrm{bp}$, which was cloned and sequenced. We sequenced 115 different cloned PCR products and obtained eight different guanylyl cyclase fragments, including two that showed high similarity to the mammalian $\alpha$ and $\beta$ sGC isoforms. We isolated the $\alpha$ subunit six times and the $\beta$ subunit four times.

The isolated fragments were used to screen a cDNA library made from prepupal abdominal nervous system. We obtained full-length cDNA clones of the Manduca homologs of both the $\alpha$ (MsGC $\alpha 1$ ) and $\beta$ (MsGC $\beta 1$ ) subunits (Fig. 2) MsGC $\alpha 1$ is a 5809 bp clone with an open reading frame spanning base pairs 235 to 2331, resulting in a protein product of 699 amino acids. MsGC $\beta 1$ is a 3691 bp clone with an open reading frame spanning base pairs 168 to 1967, resulting in a protein product of 600 amino acids. In both clones, there are termination codons upstream of the initial methionine in all three potential ORFs, and the sizes of the cDNA clones match the band size seen in Northern blot analyses (Fig. 5).

Sequence comparisons show that $\mathrm{MsGC} \alpha 1$ is more closely related to the Drosophila $\alpha$ subunit (50\% identity) (Shah and Hyde, 1995) than to the rat $\mathrm{sGC} \alpha 1$ subunit (36\% identity) (Nakane et al., 1990). When functional domains are compared between $\mathrm{MsGC} \alpha 1$ and rat $\mathrm{sGC} \alpha 1$, there is $55 \%$ identity in the catalytic domain, $63 \%$ identity in the dimerization domain, and only $16 \%$ identity in the heme-binding domain (Wedel et al., 1995; Friebe et al., 1997). Despite their low overall identity in the heme-binding domain, MsGC $\alpha 1$ has all of the 25 amino acids identified by Stone and Marletta (1995) as being conserved in all sGCs. In addition, MsGC $\alpha 1$ contains a histidine in a position homologous to that of the histidine in position 105 in the rat $\beta 1$, which is thought to be the axial ligand for interaction of heme with NO (Stone and Marletta, 1994; Wedel et al., 1994).

Sequence analysis of MsGC $\beta 1$ shows that it is approximately equally similar to the Drosophila $\beta$ subunit (56\% identity) and the rat $\beta 1$ subunit ( $58 \%$ identity). Domain comparison to the rat $\beta 1$ shows $66 \%$ identity in the catalytic domain, $72 \%$ identity in the dimerization domain, and $50 \%$ identity in the heme-binding domains. Interestingly, although MsGC $\beta 1$ has a histidine in position 105, it is missing four of the 25 highly conserved amino acids (Stone and Marletta, 1995) including the Phe-254, Phe-276, Ser-324, and Ser-341 present in the rat sGC $\beta 1$ gene. These amino acids, however, are apparently not necessary for function, because MsGC $\beta 1$ expressed in COS cells functions as a classic NO-sensitive sGC (see below). MsGC $\beta 1$ does contain the other 21 amino acids, as well as cysteines at positions 78 and 214 that 


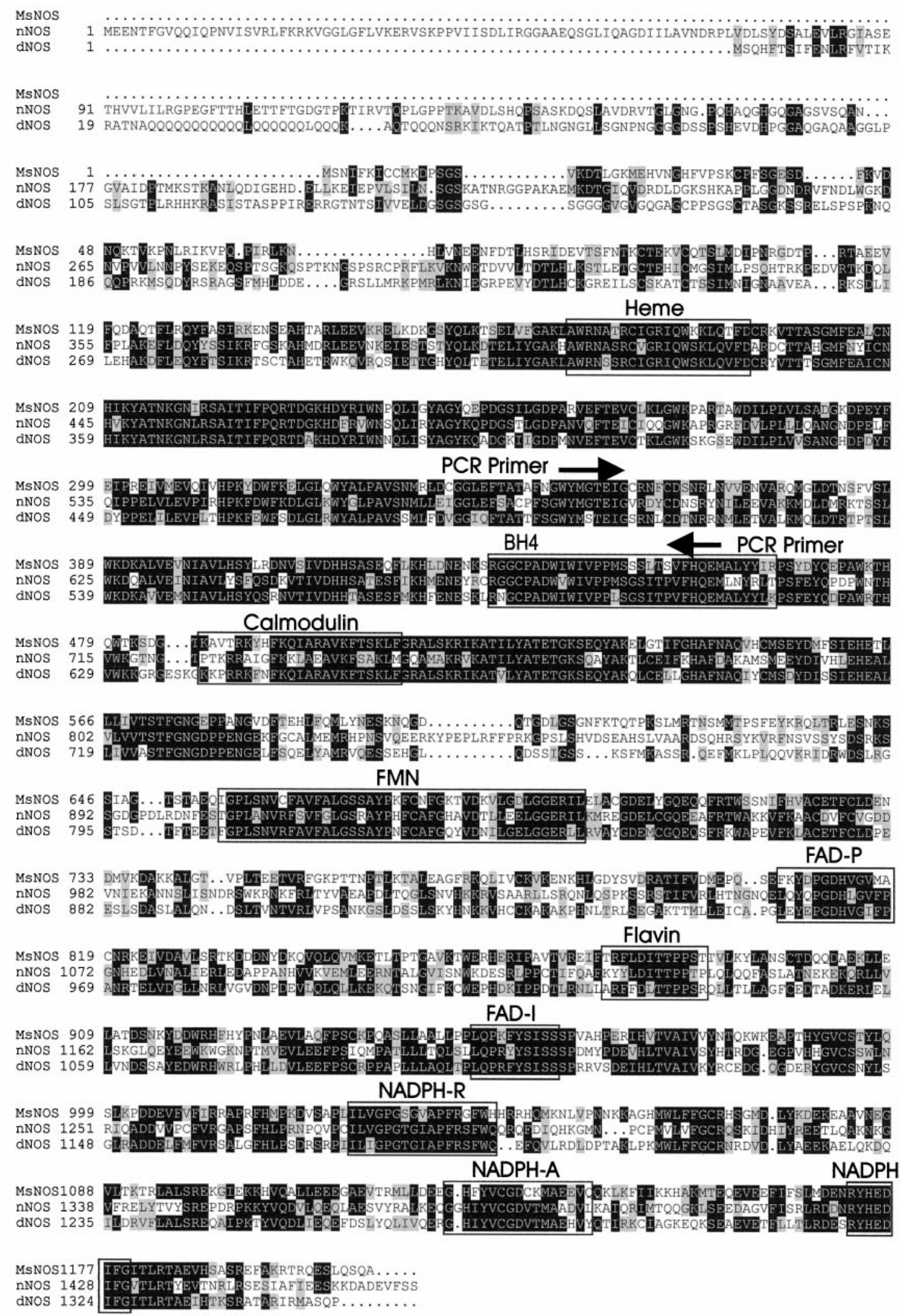

Figure 1. Amino acid alignment of MsNOS with Drosophila NOS (dNOS) and rat neuronal NOS ( $N$ NOS). The amino acid sequences were aligned using the CLUSTAL W program (Thompson et al., 1994). Identical amino acids are printed in white lettering on black background. Conserved amino acid changes are represented by black lettering on gray background. The amino acids used for degenerate primer design are denoted by arrows describing the direction of the primer. Known cofactor binding sites are labeled and boxed. Note the high levels of similarity for all three clones within the cofactor binding domains and particularly in the region from MsNOS residues 119-576. The nucleic acid sequence of MsNOS has been deposited in GenBank under accession number AF062749. 
sGC Alpha Alignment

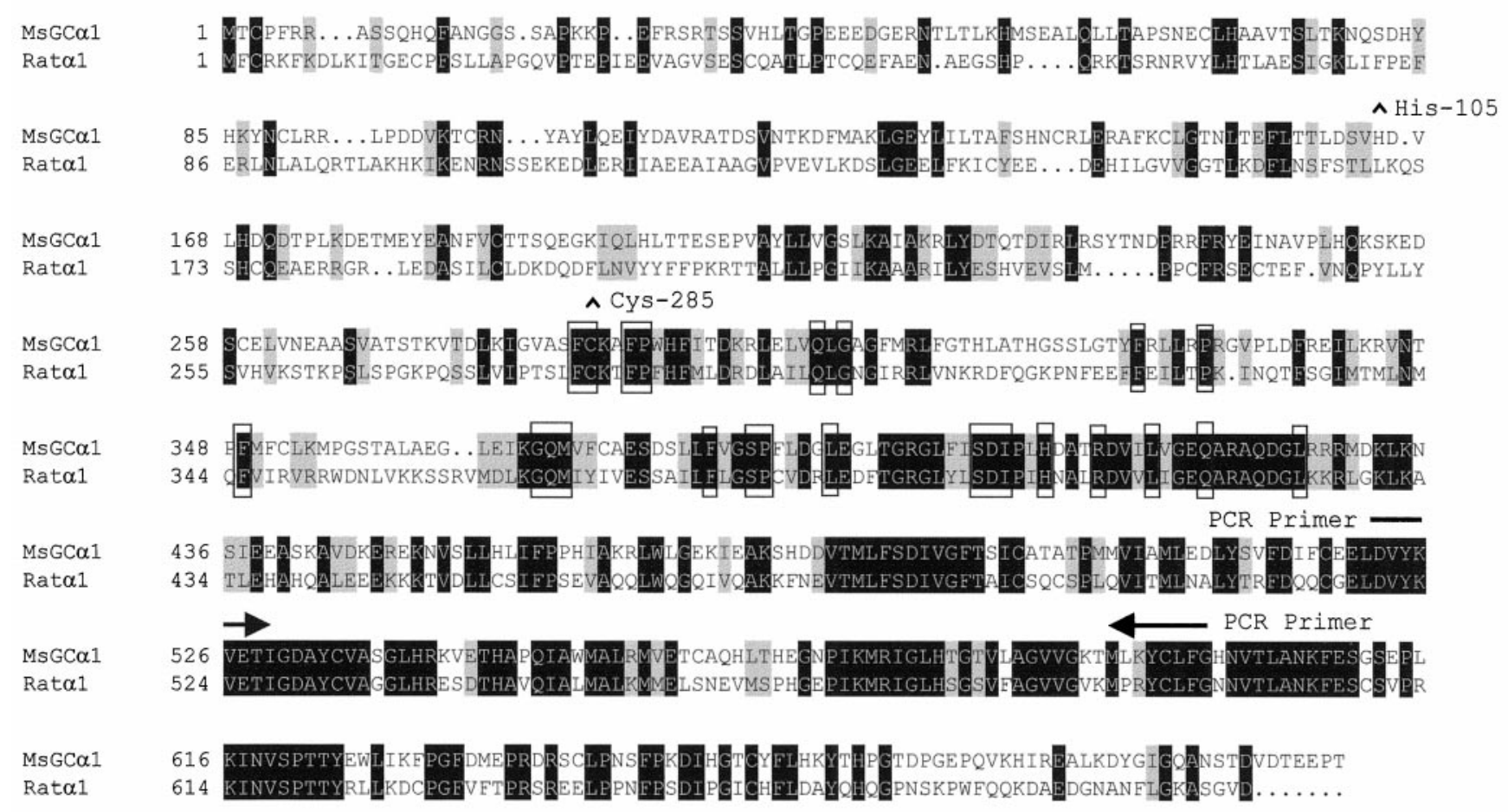

sGC Beta Alignment

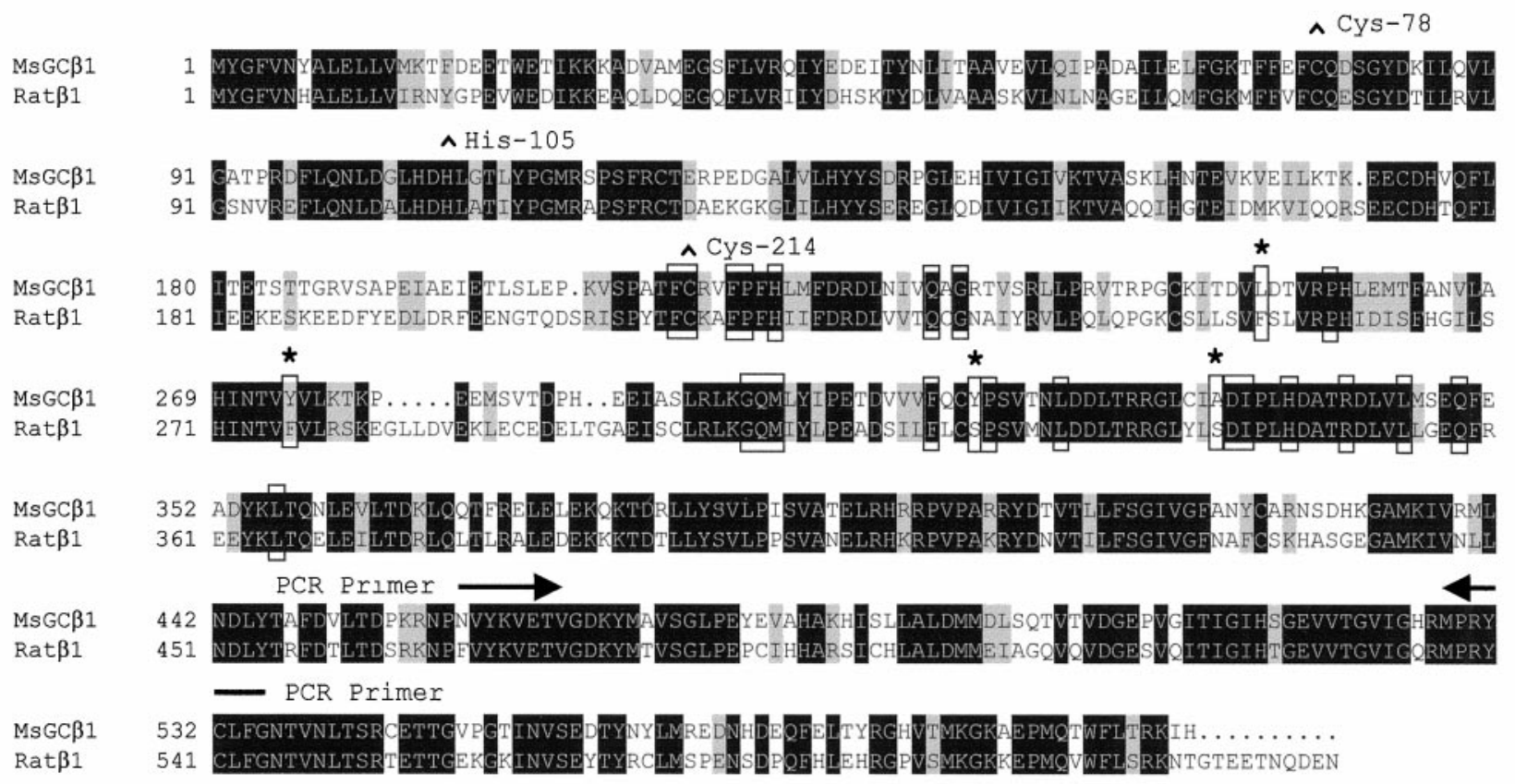

Figure 2. Amino acid alignment of the Manduca sexta sGCs with their rat homologs. The amino acid sequences were aligned using the CLUSTAL W program (Thompson et al., 1994). Identical amino acids are printed in white lettering on black background. Conserved amino acid changes are represented by black lettering on gray background. The amino acids used for degenerate primer design are denoted by arrows describing the direction of each primer. The amino acids identified by Stone and Marletta (1995) are boxed. The asterisks denote boxed residues that are not conserved in MsGC $\beta 1$. Specific amino acids shown to be important by mutational analysis are denoted by the carats, including His-105, Cys-78, and Cys-214 (labeled according to the rat sGC $\beta 1$ amino acids). Note that MsGC $\beta 1$ has all three of these residues, whereas MsGC $\alpha 1$ has the His-105 and Cys-214 homologs but is missing the Cys-78 homolog. The nucleic acid sequences of MsGC $\alpha 1$ and MsGC $\beta 1$ have been deposited into GenBank under accession numbers AF062750 and AF062751, respectively. 
A.

Manduca NOS

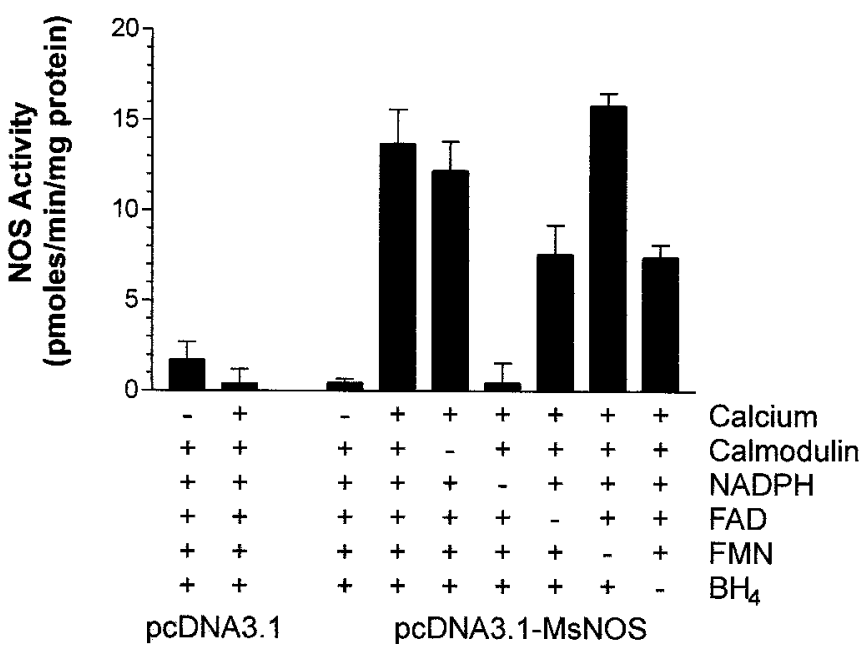

B.

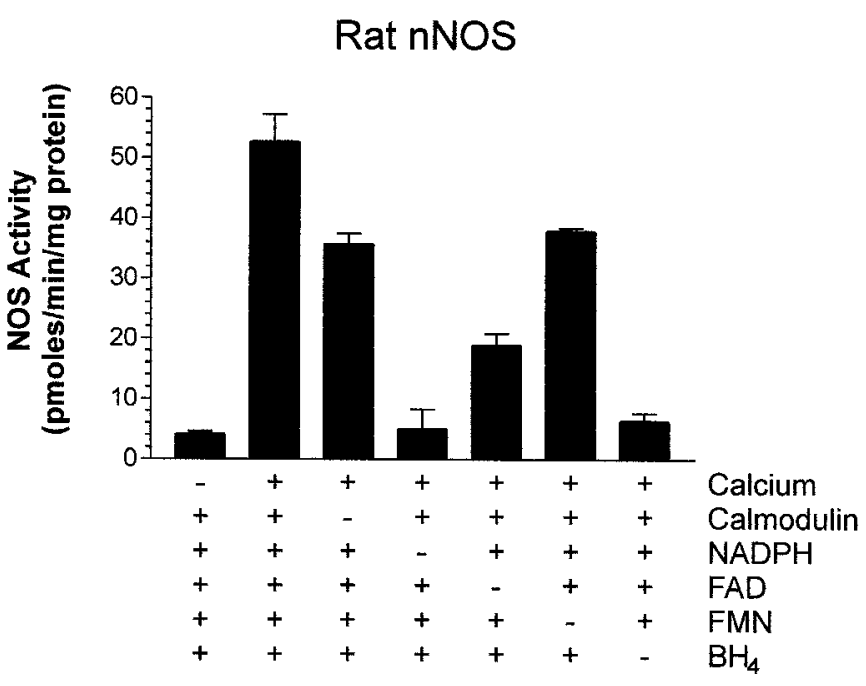

Figure 3. NOS activities of the MsNOS and rat nNOS clones after transfection into COS-7 cells. COS-7 cell homogenates were tested for their ability to convert arginine to citrulline after transfection with either vector alone $(A, p c D N A 3.1)$, MsNOS in pcDNA3.1 (A, pcDNA3.1-MsNOS), or rat nNOS in pcDNA3.1 $(B)$. Levels shown are the mean $\pm \operatorname{SEM}(n=3)$ for a single transfection experiment. A replicate transfection experiment gave an essentially similar result.

have been shown by mutational analysis to be important for NO activation of sGC (Friebe et al., 1997).

\section{The MsNOS clone appears to be biochemically similar to nNOS}

We wanted to confirm that we had obtained a functional NOS clone from Manduca sexta, and then we wanted to compare its biochemical properties to those of nNOS. We expressed our cDNA clones in COS-7 cells using transient transfection assays and measured the conversion of arginine to citrulline in COS-cell homogenates. The MsNOS clone showed significant NOS activity (Fig. 3). This activity depended on calcium and NADPH, was clearly affected by the lack of flavin adenine dinucleotide and tetrahydrobiopterin, and was relatively unaffected by loss of calmodulin and flavin mononucleotide (FMN). We transiently transfected a rat nNOS (kindly supplied by Dr. David Bredt, UCSF) in a parallel assay. In this system, with these cells and reaction conditions, the cofactor requirements for nNOS were almost identical to those of MsNOS, although the overall level of activity was higher for nNOS $(52.7 \pm 4.5 \mathrm{pmol} / \mathrm{min} / \mathrm{mg}$ protein) than for MsNOS (13.7 $\pm 1.9 \mathrm{pmol} / \mathrm{min} / \mathrm{mg}$ protein). This difference could easily be accounted for by differences in the transfection efficiencies. The two significant differences were that nNOS was more profoundly affected by the loss of exogenously added calmodulin and FMN than was MsNOS. This could actually be a result of the lower activity of the MsNOS, because the COS cells are likely to provide some endogenous calmodulin and FMN, which may have been enough to support the activity of MsNOS but not the higher activity of the nNOS. These assays clearly show, however, that we obtained a functional calcium-dependent NOS from Manduca sexta and that the protein expressed from this clone has cofactor requirements similar to those of nNOS.

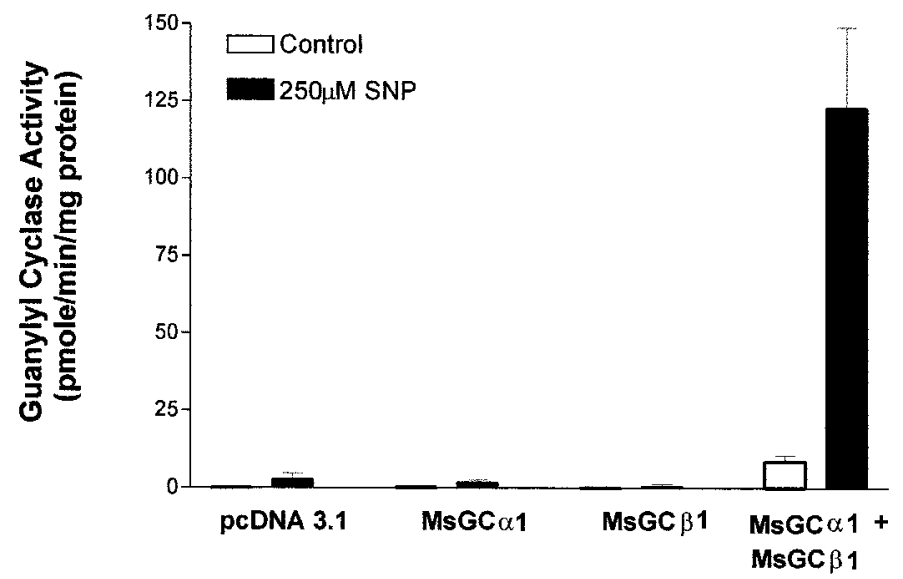

Figure 4. Guanylyl cyclase activity of MsGC $\alpha 1$ and MsGC $\beta 1$ in COS-7 cells. The guanylyl cyclase activity of COS-7 cell homogenates was tested after transfection with either vector alone ( $p c D N A 3.1), \operatorname{MsGC} \alpha 1$ in pcDNA3.1 alone $(M s G C \alpha 1), \operatorname{MsGC} \beta 1$ in pcDNA3.1 alone $(M s G C \beta 1)$, or a cotransfection experiment with both MsGC $\alpha 1$ and MsGC $\beta 1$ (MsGC $\alpha 1$ $+M s G C \beta 1$ ). Activities were examined in both the presence and absence of $250 \mathrm{~mm}$ SNP. Levels shown are the mean \pm SEM $(n=12)$ of data pooled from four separate transfection experiments.

\section{MsGC $\alpha 1$ and MsGC $\beta 1$ form a functional heterodimer}

We wanted to determine whether the Manduca sGC isoforms were functional either by themselves or as heterodimers. Again we used transient transfections to express each clone in COS-7 cells, either by itself or in a cotransfection experiment. We then measured the conversion of $\left[\alpha-{ }^{32} \mathrm{P}\right] \mathrm{GTP}$ to $\left[{ }^{32} \mathrm{P}\right] \mathrm{cGMP}$ in the presence or absence of $250 \mu \mathrm{M} \mathrm{SNP}$, an NO donor (Fig. 4). Neither subunit was active when transfected alone. When the two 
clones were cotransfected, a significant amount of basal activity was detected $(8.6 \pm 1.9 \mathrm{pmol} / \mathrm{min} / \mathrm{mg}$ of protein $)$. This basal activity was stimulated 14-fold (to $123 \pm 26 \mathrm{pmol} / \mathrm{min} / \mathrm{mg}$ of protein) in the presence of $250 \mu \mathrm{M}$ SNP. These results confirm that we have obtained Manduca sexta $\alpha$ and $\beta$ sGC isoforms, which form a functional heterodimer that can be stimulated by NO.

\section{MsNOS and Manduca sexta sGCs show nonoverlapping expression patterns}

We used Northern blot analysis to examine the tissue-specific expression patterns of each of the genes (Fig. 5). We compared the expression of each of the clones in muscle, antenna, brain, and the abdominal CNS. All of the genes were highly expressed in portions of the nervous system but not detectable in muscle. Note, however, that there was less mRNA in the muscle lane (Fig. 5). The expression pattern found within the nervous system was surprising. Both of the sGC subunits were expressed strongly in the abdominal nerve cord and brain and only weakly expressed in the antenna. The MsNOS gene, like the sGC subunits, was strongly expressed in the abdominal nerve cord but, surprisingly, only barely detectable in the brain. Moreover, the MsNOS gene was strongly expressed in the antenna. Thus, MsNOS and the Manduca sGC subunits have complementary expression patterns in the brain and antenna, with MsNOS highly expressed in the antennae and the sGC subunits highly expressed in the brain.

The MsNOS probe detected a single strong band of $6.0 \mathrm{~kb}$ in both the nerve cord and antenna and a faint $6.0 \mathrm{~kb}$ band in the brain. No evidence for additional splice forms was detected, except for a faint band of $4.3 \mathrm{~kb}$ detected in antennae. This band could represent another splice form, or because NOS has some sequence similarity to cytochrome $\mathrm{P} 450$, it could represent some weak hybridization to the cytochrome P450-like molecules, which are highly expressed in adult antennae and are thought to be involved in the clearing and degradation of odorants from the antennal lymph (Pelosi, 1995; Hovemann et al., 1997). This band was not detected in any other tissue, nor was it detected in antennae earlier in development (data not shown).

The MsGC $\alpha 1$ probe detected a single strong band of $\sim 6.0 \mathrm{~kb}$ in the abdominal nerve cord and brain and a weak band of the same size in the antenna. A weak $4.1 \mathrm{~kb}$ band of unknown significance was also found in the abdominal nerve cord. The MsGC $\beta 1$ probe detected a single strong band just below $4.0 \mathrm{~kb}$ in both the abdominal nerve cord and the brain. A weaker band of the same size was found in antennae. No other splice forms were detected. The overall expression patterns of MsGC $\alpha 1$ and MsGC $\beta 1$ appeared to be very similar to each other.

The weak MsNOS expression in the brain was surprising because of the strong NADPH-diaphorase staining observed in the antennal lobes of other insects (Elphick et al., 1995; Müller and Hildebrandt, 1995; Bicker et al., 1996). To investigate this result further, we used RT-PCR to determine whether MsNOS was present at higher levels specifically in the antennal lobes (Fig. 5). We detected a clear RT-dependent PCR product for MsGC $\alpha 1$ in both abdominal nerve cord RNA and antennal lobe RNA. We also found a clear MsNOS PCR product in abdominal nerve cord but only a faint product in antennal lobe RNA. Although these RT-PCR experiments were not done quantitatively, the faint MsNOS signal present in the antennal lobes compared with the signal in abdominal nerve cord suggests that a relatively small amount of MsNOS RNA is present in antennal lobes. This is consistent with the faint MsNOS signal found in the brain by
A
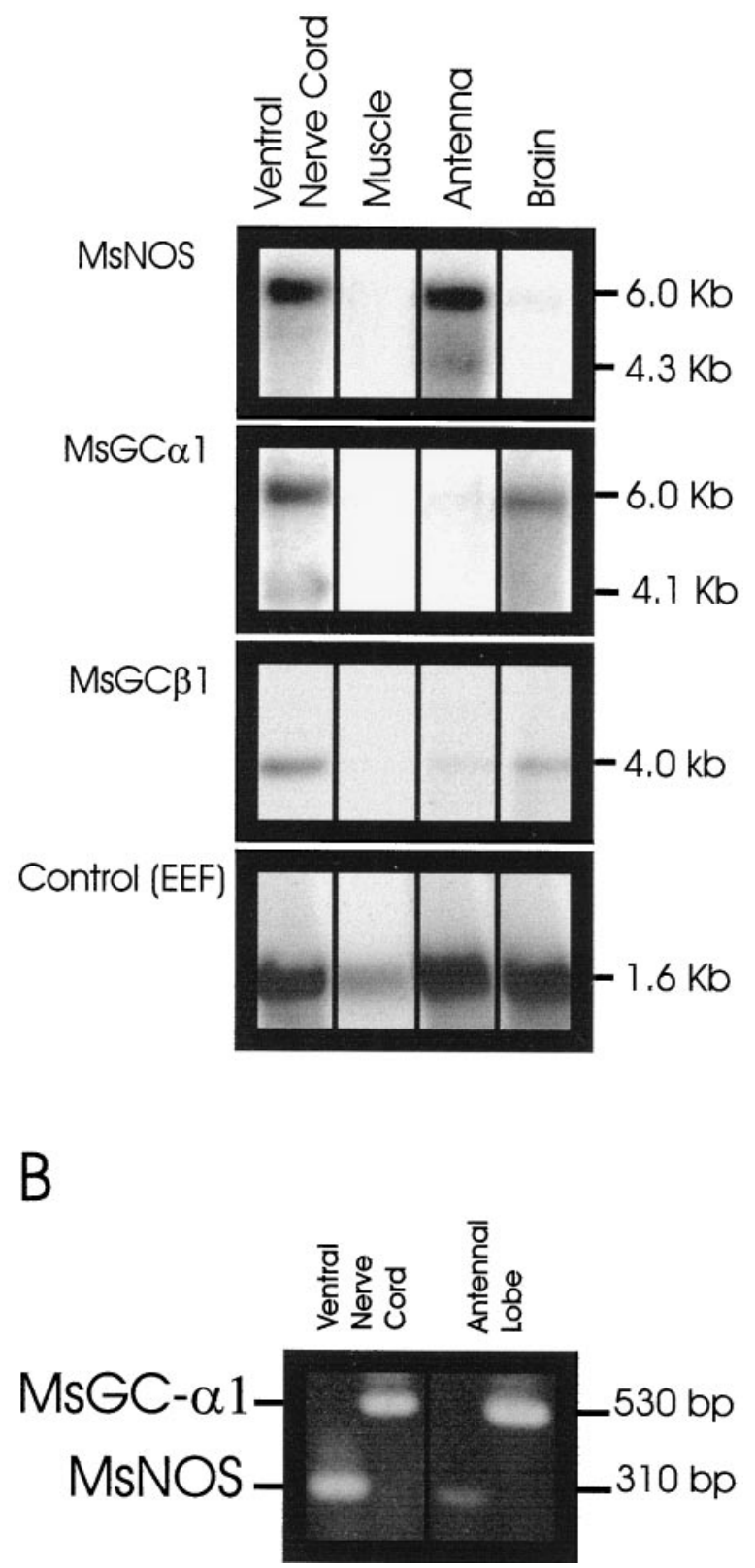

Figure 5. Northern blot and RT-PCR analyses of MsNOS and MsGC mRNA expression. $A$, Northern blot showing the expression of MsNOS, MsGC $\alpha 1$, and MsGC $\beta 1$ in different tissues. Five micrograms of poly $\left(\mathrm{A}^{+}\right)$ RNA was isolated from each tissue, separated on a $1 \%$ agarose-formaldehyde gel, and blotted onto Zetaprobe. This blot was then hybridized successively with random primed probes generated from each of the four clones. Manduca eukaryotic elongation factor 4A $(E E F)$ was used as a control for loading and for the efficiency of poly $\left(\mathrm{A}^{+}\right)$selection of the mRNA. The blot was stripped with boiling $0.1 \%$ SSC and 1\% SDS between each hybridization. The sizes of each of the bands are noted on the left in kilobases. $B$, RT-PCR of MsNOS and MsGC $\alpha 1$ in abdominal nerve cord and antennal lobe. RT-PCR was performed on total RNA isolated from the abdominal nervous system and the antennae. The resulting PCR products were separated on a $1 \%$ agarose gel and stained with ethidium bromide. A control experiment in which the reverse transcriptase was left out of the reaction was performed as a control for genomic DNA contamination. No PCR products were detected in these samples. 
Northern blot analysis and the undetectability of MsNOS in the antennal lobe by means of in situ hybridization (see below).

\section{A subset of cells in the antennal lobe express MsGC $\alpha 1$ and MsGC $\beta 1$}

To determine which cells in the antennal lobe can produce and/or respond to NO, we used in situ hybridization to determine which cells express NOS and or sGC mRNA. Most of the neuronal cell bodies in the antennal lobe are found in two groups, the lateral and the medial cell groups (see Fig. 7). The medial cell group comprises primarily projection neurons. The lateral group contains both local interneurons and projection neurons. Local interneurons are primarily inhibitory and mediate interactions among the olfactory receptor neurons and projection neurons. The projection neurons collect information from one or a few glomeruli and project out of the antennal lobe to higher brain centers.

Although the positive RT-PCR result demonstrated that the antennal lobe does express some NOS, we were unable to detect expression of MsNOS mRNA in stage 18 animals with in situ hybridization. This negative result was consistent, although the probe was able to detect mRNA expression at earlier developmental stages (data not shown), and other probes (MsGC $\alpha 1)$ used in parallel gave positive results. Because RT-PCR is much more sensitive than in situ hybridization, this finding suggests that very little MsNOS is expressed in antennal lobes. The low level of expression detected by RT-PCR could reflect a small number of cells that have high levels of MsNOS mRNA, or it could reflect a generally low level present in a larger group of cells. The lack of a signal detected by MsNOS in situ hybridization lends support to the second interpretation.

We detected a strong MsGC $\alpha 1$ signal in both the lateral and medial cell body groups of the antennal lobe. In the lateral cell group, some cells stained very darkly, a larger number of cells stained lightly, and some cells exhibited no detectable MsGC $\alpha 1$ mRNA expression. In the medial cell group, a more homogenous level of staining was observed, with all of the cells staining at an intermediate level, although some small differences among cells were detectable (Fig. 6). No expression of MsGC $\alpha 1$ mRNA was detected in the glial cells that surround the glomeruli of the antennal lobe.

MsGC $\beta 1$ mRNA expression was also observed in both the lateral and medial cell body packets (Fig. 6). The expression pattern was subtly different, however. For MsGC $\beta 1$, like MsGC $\alpha 1$, we observed three different levels of mRNA expression, but unlike the pattern for $\mathrm{MsGC} \alpha 1$, there were relatively fewer darkly staining cells and many more intermediately staining cells. Like MsGC $\alpha 1$, however, MsGC $\beta 1$ showed more homogeneous staining in the medial cell group, with all of the cells showing some level of staining. Also, like MsGC $\alpha 1$, MsGC $\beta 1$ was undetectable in glial cells of the antennal lobe.

\section{cGMP immunocytochemistry shows projection neuron staining in the antennal lobe}

To classify the antennal lobe cells that express functional sGC and to confirm that the sGC in the antennal lobe can respond to $\mathrm{NO}$, we examined the NO-stimulated levels of cGMP in the antennal lobe by means of cGMP immunocytochemistry. We stimulated the brain by incubation with SNP and then detected the resulting increase in cGMP with an anti-cGMP antibody (Fig. $6)$. We were unable to detect a cGMP signal in the absence of SNP stimulation. With SNP stimulation, however, a subset of antennal lobe neurons stained with the anti-cGMP antibody. The cell bodies as well as the processes of these cells stained, allowing us to ascertain unambiguously that some of these cells were projection neurons of both the medial and lateral cell groups. Only a subset of cells in each group stained, with some minor variations in the level of staining among the cells that did stain. Nuclear staining was evident within some of the cells that stained. The significance of the nuclear localization of cGMP in these cells is unknown, but it is intriguing to speculate that cGMP might mediate changes in gene expression. There was also strong staining in some of the projection neuron processes enervating the macroglomerular complex (MGC), a male-specific glomerular complex involved in the processing of pheromonal information (Christensen and Hildebrand, 1987). These results suggest that at least some of the projection neurons within the antennal lobe can respond to NO with an increase in cGMP.

Note that fewer cells exhibited detectable levels of cGMP after SNP stimulation than were positive for sGC expression as determined by in situ hybridization. This is most likely attributable to the relatively low sensitivity of the anti-cGMP antibody (Morton, 1996). Another possibility is that this difference reflects regulation of the NO sensitivity of the sGCs within the cells that express them (see Discussion). There was some variability from preparation to preparation using this method. Although in each brain approximately the same number of cells stained in each experiment, these cells appeared to extend into a slightly different subset of glomeruli in each animal. Within each individual, however, the pattern was primarily similar in both antennal lobes. One constant from all individuals examined $(n=8)$ was that some projection neurons from the MGC were always stained. These results are consistent with the concept that a subset of antennal lobe neurons express NO-sensitive sGC and that this subset of cells consists primarily of projection neurons.

\section{DISCUSSION}

To study the roles of NO in the olfactory system of Manduca sexta, we have cloned NOS (MsNOS) and both the $\alpha$ (MsGC $\alpha 1)$ and $\beta$ (MsGC $\beta 1$ ) subunits of sGC from the Manduca nervous system. Sequence comparisons show that MsNOS is more closely related to other known insect NOS genes than to any of the mammalian NOS isoforms. Of the mammalian isoforms, MsNOS is more closely related to nNOS than to either iNOS or eNOS. Most importantly, MsNOS is functional and displays biochemical properties similar to nNOS, including its sensitivity to exogenous $\mathrm{Ca}^{2+}$.

The Manduca sGCs appear to be functional homologs of the mammalian sGCs. Transient expression experiments suggest that they are obligate heterodimers that are sensitive to stimulation by NO. Although we do not know exactly which amino acids are required for the function of the dimerization and heme-binding domains, comparison across species can yield valuable clues. Stone and Marletta (1995) have done this comparison with the putative heme-binding and dimerization domains of sGC subunits. They identified 25 residues that are conserved in all of the sequences examined. All 25 of these residues are present in MsGC $\alpha 1$, but four of them are missing in MsGC $\beta 1$, although MsGC $\beta 1$ is more similar to its mammalian homolog. Because three of the four substitutions are not conservative (Fig. 2), this result suggests that these four amino acids are not absolutely required for function. The number of conserved residues present in the heme-binding and dimerization domains of sGC subunits is thus reduced to 21 . 

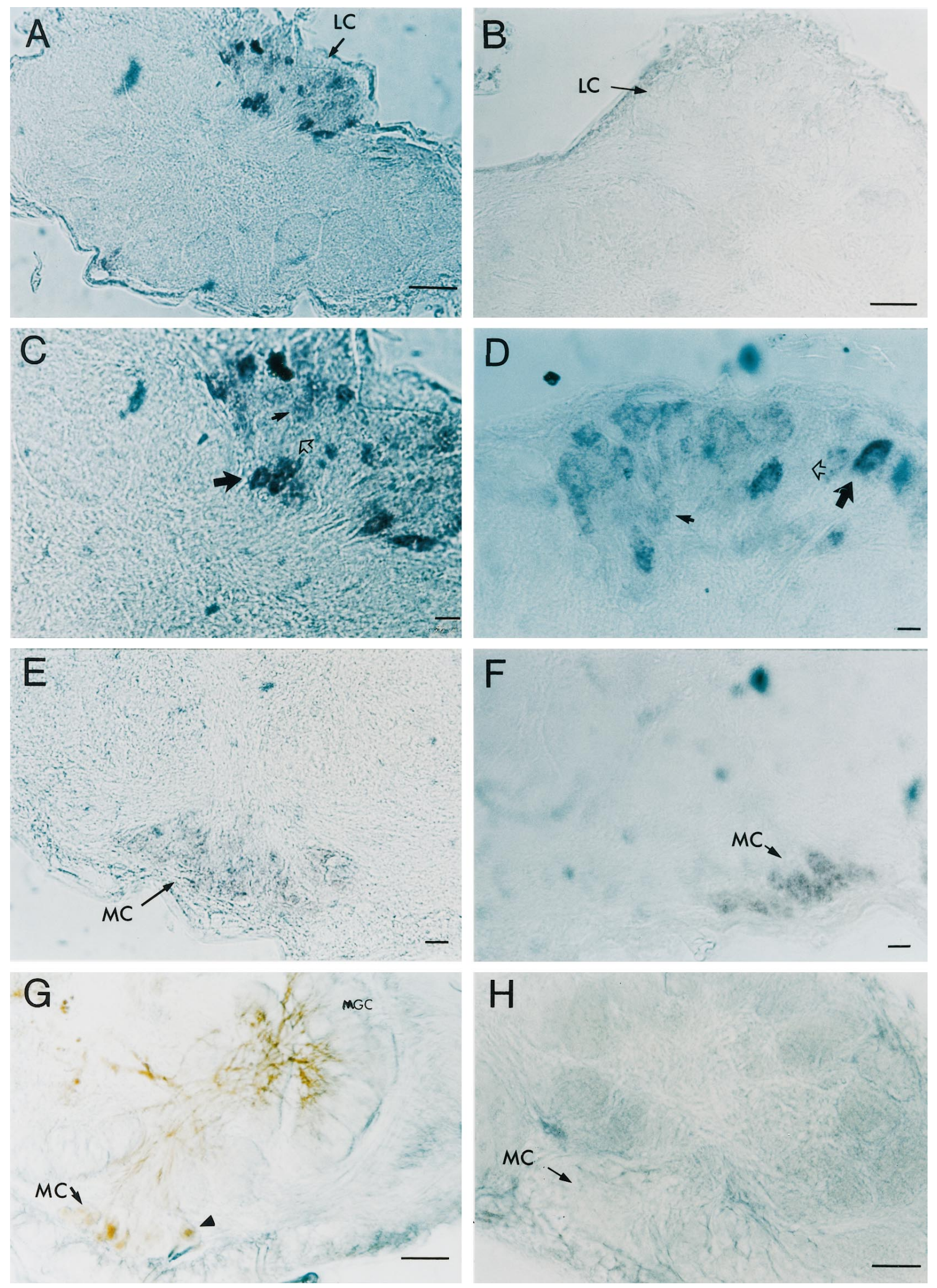

Figure 6. Localization of MsGC $\alpha 1$, MsGC $\beta 1$, and SNP-stimulated cGMP in the Manduca antennal lobe. $A-F$, In situ hybridization with MsGC $\alpha 1$ and MsGC $\beta 1$ probes. $A$, Low-magnification view of antennal lobe probed with MsGC $\alpha 1$ antisense probe. Note the lateral cell body cluster $(L C)$ staining and the lack of staining in any other structure. $B$, Low-magnification view of the antennal lobe probed with a MsGC $\alpha 1$ sense control probe. Note the lack of any detectable staining. A section through the lateral cell cluster $(L C)$ is shown. $C$, High-magnification view of the lateral cell cluster shown in $A$ (MsGC $\alpha 1$ antisense probe). A darkly staining cell (large arrow), a lightly staining cell (small arrow), and a nonstaining cell (Figure legend continues) 


\section{The sensitivity of a particular neuron to NO may be partially regulated by SGC expression}

Formation of functional sGC requires coexpression of MsGC $\alpha 1$ and MsGC $\beta 1$. In situ hybridization studies of antennal lobe neurons show that $\sim 90 \%$ of those neurons express detectable levels of MsGC $\beta 1$ and that $\sim 60-70 \%$ express detectable levels of MsGC $\alpha 1$. Thus, it is clear that a large proportion of antennal lobe neurons express both subunits. The ability of MsGC $\alpha 1$ and MsGC $\beta 1$ heterodimers to be activated in vivo is supported by the ability of the anti-cGMP antibody to detect significant elevations of cGMP in a subset of projection neurons in response to NO. Fewer neurons can be detected with this method, however, than would be predicted to express active sGC by the in situ hybridization analysis. This is possibly explained by the difference in sensitivity of the two methods, although the medial cell packet showed the highest sensitivity to $\mathrm{NO}$, whereas the lateral cell packet had the highest levels of sGC expression. This suggests that the sensitivity of sGC to NO may be regulated. Thus, the efficacy of the NO-cGMP pathway may be determined both by the activity of NOS as well as the sensitivity of the sGC. If regulation of the NO sensitivity of the projection neurons occurs in the antennal lobe, it would have important functional implications. It might imply, for example, that sensitivity of the organism to a particular odorant could be altered in response to changing physiological conditions by changing the sensitivity of a subset of antennal lobe neurons to NO.

If the ability of a particular neuron to respond to $\mathrm{NO}$ is regulated, does the pattern of expression of the sGC subunits reflect that regulation? The expression pattern of MsGC $\alpha 1$ and MsGC $\beta 1$ in the antennal lobe parallels the expression pattern of the sGC subunits in the mammalian olfactory bulb (Hopkins et al., 1996), with MsGC $\beta 1$ widely expressed and MsGC $\alpha 1$ showing large variations among cells. This difference in the regulation of the two subunits could reflect two different possibilities. First, one or more as yet unidentified MsGC $\alpha$ subunits could be present in those cells. If this is the case, the sensitivity of a neuron to NO could be controlled by the nature of the different $\mathrm{sGC} \alpha$ subunits expressed in that neuron. A second possibility is that the responsiveness of some subsets of cells could be controlled by the amount of MsGC $\alpha 1$ expressed in them at any given time, with MsGC $\beta 1$ always expressed and ready to form heterodimers. Although this possibility might account for the differential sensitivity to NO of different antennal lobe neurons in the lateral cell group, it cannot account for differences among neurons in the medial group, because both subunits are expressed at approximately equal levels in all of those neurons. The evidence to date suggests that the expression pattern of the sGC-subunit mRNA can account for some of the differences among antennal lobe neurons, most obviously those in which no sGC expression is detected. It cannot, however, account for all of the apparent differential sensitivity to NO. There may be additional levels of regulation at the level of the protein.
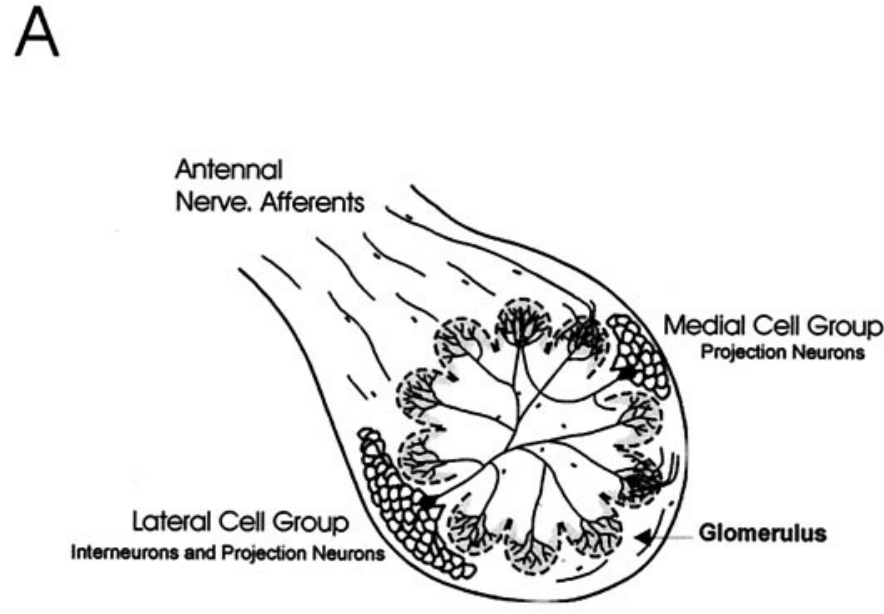

B

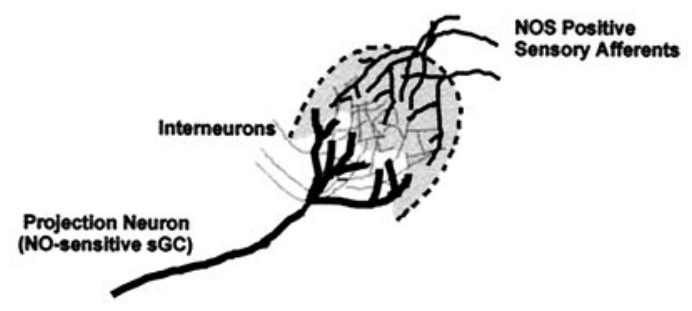

Figure 7. Schematic diagram of a Manduca antennal lobe. A, General overview. The antennal lobe consists of a glomerular neuropil. Each glomerulus is surrounded by a glial border (dotted lines). Antennal lobe neurons have their cells bodies in either the medial cell group (containing projection neurons only) or the lateral cell group (containing both projection and interneurons). Olfactory receptor neurons from the antennae send axons down the antennal nerve in the antennal lobe. In the lobe, sensory afferents project to the outer portions of glomeruli. Interneurons send processes into multiple glomeruli. Projection neurons have dendrites projecting into one or more glomeruli and send their axons to higher brain centers. $B$, Close-up of a glomerulus. In this close-up view of an individual glomerulus, the relationships between the sensory afferents (medium lines), interneurons (thin lines), and projection neurons (thick lines) are shown.

\section{Functional implications of the MsNOS and MsGC expression patterns for the roles of NO in antennal lobe}

Using the clones described in this paper, we now can explore the roles of NO in the olfactory system. We have shown that NOsensitive sGC is expressed at relatively high levels in the antennal lobes and at comparatively low levels in the antennae. Because neurons in both the lateral and medial cell groups of the antennal

\footnotetext{
(open arrowhead) are shown. D, High-magnification view of the lateral cell cluster probed with MsGC $\beta 1$ antisense probe. Darkly staining (large arrow), lightly staining (small arrow), and nonstaining cells (open arrowhead) are shown. $E$, High-power view of the medial cell cluster (MC) probed with MsGC $\alpha 1$ antisense probe. Note the general light level of staining in all cells. $F$, High-magnification view of the medial cell cluster (MC) probed with MsGC $\beta 1$ antisense probe. Note the general light level of staining in all cells. $G, H$, cGMP immunocytochemistry. $G$, Low-magnification view of an antennal lobe stimulated with SNP and stained with an anti-cGMP antibody. Staining of cell bodies in the medial cell cluster (MC) is shown. Note the nuclear staining present in some cells (arrowhead). The processes of these cells are clearly seen, including dendrites in the macroglomerular complex neuropil (MGC). $H$, Low-magnification view of an antennal lobe not treated with SNP but stained with the anti-cGMP antibody. Note the lack of any detectable staining. Scale bars: $A, B, G, H, 400 \mu \mathrm{M} ; C-F, 100 \mu \mathrm{M}$.
} 
lobe (Fig. 7) express sGC subunits, we predict that at least some projection neurons can respond to NO with an increase in cGMP. Moreover, because both interneurons and projection neurons are present in the lateral cell group, it is possible that representatives of both classes of neurons can respond to a NO signal. The NO-stimulated cGMP increases measured with immunohistochemistry, however, suggest that projection neurons are the main target of NO produced in the antennal lobe.

The relative lack of MsNOS expression in the antennal lobes is surprising in view of the high levels of NADPH-diaphorase staining in insect antennal lobes shown previously. There could be several different explanations for this finding. First, MsNOS mRNA levels may not accurately reflect the levels of the NOS protein or protein activity. In view of the fact that MsNOS mRNA is expressed at high levels in antennal lobes early in development (A. Nighorn and N.J. Gibson, unpublished observations), it is possible that the protein product generated at that time is maintained and that there is no need for additional message in the adult. Second, NADPH-diaphorase staining may not specifically detect MsNOS. Other enzymes could be detected by this relatively nonspecific histochemical method. Third, it is possible that other as yet unidentified forms of NOS are responsible for the NADPH-diaphorase staining in the brain. The Northern and Southern blot analyses, however, show no evidence of any additional splice variants or other forms of NOS, except possibly in the antenna. We cannot, however, rule out the possibility that NOS expression in the brain is inducible and that we have not examined its expression under the proper stimulatory conditions, especially because these animals were not yet fully functional adults. It is also possible, although unlikely, that the small amount of MsNOS that we could detect is sufficient to fully activate the sGC.

Whether NADPH-diaphorase staining does or does not accurately reflect MsNOS protein expression, we also have to consider that NO is not the only way of stimulating sGC. CO, for example, stimulates sGC in a manner similar to NO (Kharitonov et al., 1995). The noncoincident expression patterns of Manduca sGC and MsNOS may reflect that the sGC in those locations in which MsNOS is absent is activated by CO or some other mechanism.

Another, more interesting, explanation of the lack of NOS message specifically in the antennal lobe is suggested by the high level of MsNOS expression in the antenna. MsNOS may be expressed in olfactory receptor cells (ORCs) in which NADPHdiaphorase staining has been demonstrated (Stengl and Zintl, 1996). MsNOS might then be transported down the axons and be highly enriched in the glomeruli of the antennal lobe where the ORCs interact with interneurons and, indirectly, with projection neurons. Because projection neurons are the most sensitive to NO, as measured by immunocytochemistry after NO stimulation, they are the most likely targets of NO generated within the glomerulus. Thus, NO may provide a mechanism by which the ORCs may bypass the inhibitory interneurons to affect the excitability of the projection neurons directly (Fig. 7). An NOS immunocytochemical study will be necessary to determine whether NOS protein is indeed localized to the ORC axons.

In summary, we have cloned MsNOS, MsGC $\alpha 1$, and MsGC $\beta 1$ from the Manduca sexta nervous system. We have demonstrated that these clones are functional when expressed in a heterologous cell system. MsNOS converts arginine to citrulline and shows similar cofactor requirements to rat nNOS. MsGC $\alpha 1$ and MsGC $\beta 1$ act as obligate heterodimers and can be stimulated by NO. We found that MsNOS is enriched in antennae, whereas
MsGC $\alpha 1$ and MsGC $\beta 1$ are enriched in antennal lobes, suggesting that the ORCs from the antennae may express NOS in their axons and provide a means of communication within the glomeruli of the antennal lobe. In this way, the ORCs could bypass interneurons and directly activate projection neurons, or they could interact nonsynaptically with a subset of interneurons. The function of these potential interactions remains unidentified.

\section{REFERENCES}

Angerer LM, Angerer RC (1992) In situ hybridization to cellular RNA with radiolabeled RNA probes. In: In situ hybridization: a practical approach, pp 16-32. New York: Oxford UP.

Bicker G, Schmachtenberg O, De Vente J (1996) The nitric oxide/cyclic GMP messenger system in olfactory pathways of the locust brain. Eur J Neurosci 8:2635-2643.

Bredt DS, Schmidt HHHW (1996) The citrulline assay. In: Methods in nitric oxide research (Feelisch M, Stamler JS, eds), pp 249-255. New York: Wiley.

Breer H, Shepherd GM (1993) Implications of the NO/cGMP system for olfaction. Trends Neurosci 16:5-9.

Brenman JE, Chao DS, Gee SH, McGee AW, Craven SE, Froehner SC, Bredt DS (1996) Interaction of nitric oxide synthase with the postsynaptic density protein PDS-95 and alpha1-syntrophin mediated by PDZ domains. Cell 84:757-767.

Chinkers M, Garbers DL (1991) Signal transduction by guanylyl cyclases. Annu Rev Biochem 60:553-575.

Christensen TA, Hildebrand JG (1987) Male-specific sex pheromoneselective projection neurons in the antennal lobes of the moth Manduca sexta. J Comp Physiol [A] 160:553-569.

Elphick MR, Rayne RC, Riveros-Moreno V, Moncada S, O'Shea M (1995) Nitric oxide synthesis in locust olfactory interneurons. J. Exp Biol 198:821-829.

Friebe A, Wedel B, Harteneck C, Foerster J, Schultz G, Koesling D (1997) Functions of conserved cysteines of soluble guanylyl cyclases. Biochemistry 36:1194-1198.

Garbers DL (1992) Guanylyl cyclase receptors and their endocrine, paracrine, and autocrine ligands. Cell 71:1-4.

Hopkins DA, Steinbusch HWM, Karkerink-Van Ittersum M, De Vente J (1996) Nitric oxide synthase, cGMP, and NO-mediated cGMP production in the olfactory bulb of the rat. J Comp Neurol 375:641-658.

Hovemann BT, Sehlmeyer F, Malz J (1997) Drosophila melanogaster NADPH-cytochrome P450 oxidoreductase: pronounced expression in antennae may be related to odorant clearance. Gene 189:213-219.

Jaffrey SR, Snyder SH (1996) PIN: an associated protein inhibitor of neuronal nitric oxide synthase. Science 274:774-777.

Kendrick KM, Guevara-Guzman R, Zorilla J, Hinton MR, Broad KD, Mimmack M, Ohkura S (1997) Formation of olfactory memories mediated by nitric oxide. Nature 388:670-674.

Kharitonov VG, Sharma VS, Pilz RB, Madge D, Koesling D (1995) Basis of guanylate cyclase activation by carbon dioxide. Proc Natl Acad Sci USA 92:2568-2571.

Kishimoto J, Keverne EB, Hardwick J, Emson PC (1993) Localization of nitric oxide synthase in the mouse olfactory and vomeronasal system: a histochemical, immunological and in situ hybridization study. Eur J Neurosci 5:1684-1694.

Komminoth P (1996) Detection of mRNA in tissue sections using DIGlabeled RNA and oligonucleotide probes. In: Nonradioactive in situ hybridization application manual, Ed 2 (Grünewald-Janho S, Keesey J, Leous M, van Miltenburg R, Schroeder C, eds), pp. 126-135. Ingelheim am Rhein, Germany: Boehringer Ingelheim International GmbH.

Morton DB (1996) Neuropeptide-stimulated cyclic guanosine monophosphate immunoreactivity in the neurosecretory terminals of a neurohemal organ. J Neurobiol 29:341-353.

Morton DB, Giunta MA (1992) Eclosion hormone stimulates cGMP levels in Manduca sexta nervous tissue via arachidonic acid metabolism with little or no contribution from the production of nitric oxide. J Neurochem 59:1522-1530.

Müller U (1996) Inhibition of nitric oxide synthase impairs a distinct form of long-term memory in the honeybee, Apis mellifera. Neuron 16:541-549.

Müller U, Hildebrandt H (1995) The nitric oxide/cGMP system in the antennal lobe of Apis mellifera is implicated in integrative processing of chemosensory stimuli. Eur J Neurosci 7:2240-2248. 
Nakane M, Murad F (1994) Cloning of guanylyl cyclase isoforms. Adv Pharmacol 26:7-18.

Nakane M, Arai K, Saheki S, Kuno T, Buechler W, Murad F (1990) Molecular cloning and expression of cDNAs coding for soluble guanylyl cyclase from rat lung. J Biol Chem 265:16841-16845.

O'Dell TJ, Hawkins RD, Kandel ER, Arancio O (1991) Tests on the roles of two diff usible substances in LTP: evidence for nitric oxide as a possible early retrograde messenger. Proc Natl Acad Sci USA 88:11285-11289.

Okere CO, Kaba H, Higuchi T (1996) Formation of an olfactory recognition memory in mice: reassessment of the role of nitric oxide. Neuroscience 71:349-354.

Pelosi P (1995) Perireceptor events in olfaction. J Neurobiol 30:3-19.

Prescott DJ, Hildebrand JG, Sanes JA, Jewett S (1977) Biochemical and developmental studies of acetylcholine metabolism in the central nervous system of the moth, Manduca sexta. Comp Biochem Physiol 56:77-84.

Regulski M, Tully T (1995) Molecular and biochemical characterization of dNOS: a Drosophila $\mathrm{Ca}^{++} /$calmodulin-dependent nitric oxide synthase. Proc Natl Acad Sci USA 92:9072-9076.

Sanes JR, Hildebrand JG (1976) Structure and development of antennae in a moth, Manduca sexta. Dev Biol 151:282-299.

Schachtner J, Truman JW, Homberg U (1998) The NO/cGMP signaling pathway in the developing antennal lobe of the tobacco hornworm Manduca sexta. In: New Neuroethology On The Move. Proceedings of the 26th Goettingen Neurobiology Conference. (Elsner N, Wehner R, eds) New York: Thieme.

Schmidt HH, Gagne GD, Nakane M, Pollock JS, Miller MF, Murad F (1992) Mapping of neural nitric oxide synthase in the rat suggests frequent co-localization with NADPH diaphorase but not with soluble guanylyl cyclase, and novel paraneural functions for nitrinergic signal transduction. J Histochem Cytochem 40:1439-1456.
Schuman EM, Madison DV (1994) Nitric oxide and synaptic function. Annu Rev Neurosci 17:153-183.

Shah S, Hyde DR (1995) Two Drosophila genes that encode the alpha and beta subunits of soluble guanylyl cyclase. J Biol Chem 270:15368-15376.

Stengl M, Zintl R (1996) NADPH diaphorase activity in the antennae of the hawkmoth Manduca sexta. J Exp Biol 199:1063-1072.

Stone JR, Marletta MA (1994) Soluble guanylyl cyclase from bovine lung: activation with nitric oxide and carbon monoxide and spectral characterization of the ferrous and ferric states. Biochemistry 33:5636-5640.

Stone JR, Marletta MA (1995) Heme stoichiometry of heterodimeric soluble guanylate cyclase. Biochemistry 34:14668-14674.

Thompson JD, Higgins DG, Gibson TJ (1994) CLUSTAL W: improving the sensitivity of progressive multiple sequence alignment through sequence weighting, position-specific gap penalties and weight matrix choice. Nucleic Acids Res 22:4673-4680.

Tolbert LP, Matsumoto SG, Hildebrand JG (1983) Development of synapses in the antennal lobes of the moth Manduca sexta during metamorphosis. J Neurosci 3:1158-1175.

Truman JW, Taghert PH, Reynolds SE (1980) Physiology of pupal ecdysis in the tobacco hornworm Manduca sexta. I. Evidence for control by eclosion hormone. J Exp Biol 88:327-337.

Wedel B, Humbert P, Harteneck C, Foester J, Malkewitz J, Böhme E, Schultz G, Koesling D (1994) Mutation of His-105 in the $\beta_{1}$ subunit yields a nitric oxide-insensitive form of soluble guanylyl cyclase. Proc Natl Acad Sci USA 91:2592-2596.

Wedel B, Harteneck C, Foester J, Friebe A, Schultz G, Koesling D (1995) Functional domains of soluble guanylyl cyclase. J Biol Chem 270:24871-24875.

Yuda M, Hirai M, Matsumura H, Ando K, Chinzei Y (1996) cDNA cloning, expression, and characterization of nitric oxide synthase from the salivary glands of the blood-sucking insect Rhodnius prolixus. Eur J Biochem 242:807-812. 